\title{
Öğretmen ve Öğrencilere Göre 4006 TÜBITAK Bilim Fuarları Etkililikleri: Geçerlik ve Güvenirlik Çalışması ${ }^{1}$
}

\author{
Gülenaz SELÇUK \\ Dr. Öğr. Üyesi, Manisa Celal Bayar Üniversitesi, \\ Eğitim Fakültesi, Eğitim Bilimleri Bölümü \\ gselcuk@hotmail.com \\ Orcid ID: https://orcid.org/0000-0002-3578-6010
}

\section{Erkan Hasan ATALMIŞ}

Doç. Dr., Kahramanmaraş Sütçü İmam Üniversitesi, Eğitim Fakültesi, Eğitim Bilimleri Bölümü erkanatalmis@gmail.com

Orcid ID: https://orcid.org/0000-0001-9610-491X

\author{
Ahmet ATAÇ \\ Prof. Dr., Manisa Celal Bayar Üniversitesi, \\ Fen Edebiyat Fakültesi, Fizik Bölümü \\ ahmet.atac@cbu.edu.tr \\ Orcid ID: https://orcid.org/0000-0003-1574-366X
}

\section{Öz}

Bu çalışmanın amacı öğretmen ve öğrencilere göre "4006 TÜBİTAK Bilim Fuarları Etkililikleri” ölçeklerini geliştirmektir. Çalışmanın örneklemini Kahramanmaraş ili Milli Eğitim Müdürlüğüne bağlı okullardan basit seçkisiz olarak belirlenmiş 348 öğretmen ve 367 öğrenci oluşturmaktadır. Ölçeklerin yapı geçerliklerini ölçmek için çapraz geçerleme prosedürü uygulanarak açımlayıcı ve doğrulayıcı faktör analizi yapılmıştır. Çalışma sonunda, öğrencilere göre "4006 TÜBİTAK Bilim Fuarları Etkililik Ölçeği” 35 madde ve tek boyutlu olarak bulunurken, öğretmenlere göre "4006 TÜBİTAK Bilim Fuarları Etkililik Ölçeği”" 46 madde ve üç boyutlu olarak bulunmuştur. Ölçeklerin güvenirlikleri için Croanbach Alpha iç tutarlılık katsayısı ile hesaplanmış ve sırasıyla .93 ve .99 olarak bulunmuştur. Çalışma sonunda elde edilen bulgular geliştirilen bu ölçeğin hem geçerliğini hem de güvenirliğini desteklemektedir.

\footnotetext{
${ }^{1}$ Makale Geliş/Kabul Tarihi: 16.07.2020 / 05.09.2020

Künye Bilgisi: Selçuk, G.; Atalmış, E.H. ve Ataç, A. (2020). Öğretmen ve Öğrencilere Göre 4006 TÜBITAK Bilim Fuarları Etkililikleri: Geçerlik ve Güvenirlik Çalışması. Kahramanmaraş Sütçü İmam Üniversitesi Sosyal Bilimler Dergisi, 17 (2), 750-774. DOI: 10.33437/ksusbd.770025
} 
G. Selcuk-E.H. Atalmıs-A. Atac Öğgretmen ve Öğgrencilere Göre 4006...

Anahtar Kelimeler: TÜBITAK 4006, Bilim Fuarı, Ölçek Geliştirme, Güvenirlik ve Geçerlik.

\title{
4006 TUBITAK Science Fairs Effectiveness According to Teachers and Students: Validity and Reliability Study
}

\begin{abstract}
The purpose of this study is to develop the "4006 TUBITAK Science Fairs Effectiveness" scales according to students and teachers. The sample of the study consisted of 367 students and 348 teachers who were randomly selected from the schools affiliated to National Education Ministry in Kahramanmaraş. In order to measure the structure validity of the scales, exploratory factor analysis and confirmatory factor analysis were performed by applying a cross-validation procedure. At the end of the study, "4006 TÜBITAK Science Fairs effectiveness Scale" according to students was found to be 35 items and one factor while "4006 TÜBITAK science fairs effectiveness scale" according to teachers was found to be 46 items and three-factors. For the reliability of the scales, Croanbach Alpha was calculated with the internal consistency coefficient and found as .93 and .99, respectively.The findings of the study support both the validity and reliability of this developed scale.
\end{abstract}

Keywords: TÜBİTAK 4006, Science Fair, Scale Development, Reliability and Validity.

\section{GíRiş}

Eğitim ve okul kavramları yaşamın her alanında insanoğlunun karşısına çıkmakta ve bu kavramlara yönelik farklı farklı tanımlar yapılmaktadır. Türk Dil Kurumu (2011)'na göre eğitim tanımı "Çocukların ve gençlerin toplum yaşayışında yerlerini almaları için gerekli bilgi, beceri ve anlayışları elde etmelerine, kişiliklerini geliştirmelerine okul içinde veya dışında, doğrudan veya dolaylı yardım etme, terbiye:" olarak yapılırken, okul ise "Her türlü eğitim ve öğretimin toplu olarak yapıldığı yer, mektep" olarak tanımlanmaktadır. Bu tanımlar birleştirildiğinde okul, bireylerin yaşam içerisinde kullanacakları gerekli bilgi, becerileri ve davranışların öğretildiği yer olarak da tanımlanabilmektedir.

Küreselleşen ve bilgi teknojisinin hızla ilerlediği dünyada çağın gerekli olan bu beceleri için "21.yüzyıl beceri" kavramı ortaya çıkmıştır. 21 yy. becerileri 
birçok kurum ve kuruluş farklı tanımlanmasına rağmen, bunlar arasında saygın olanlarından biri Partnership For 21st Century Skills - 21. Yüzy1l Becerileri İçin Ortaklık - (P21)'de üç ana başlıkta olup toplam 13 beceriden oluşmaktadır (Partnership For 21st Century Skills, 2013). Öğrenme ve yenilikçilik becerileri; yaratıcı düşünme, eleştirel düşünme, problem çözme, iletişim, işbirliği; bilgi, medya ve teknoloji becerileri; bilgi okuryazarlı̆̆l, bilgi ve iletişim teknolojileri okuryazarlığl, medya okuryazarlığ uyum, kendini yönetme, sosyal beceriler, üretkenlik ve hesap verebilirlik, liderlik şeklinde kategorize edilmektedir. Bu beceriler Avrupa komisyonu (2007) tarafından belirlenen yaşam boyu öğrenmede anahtar yeterlikleri ile büyük ölçüde örtüşmektedir. "Yaşam Boyu Öğrenmede Anahtar Yeterlikler-Avrupa Çerçevesi", Avrupa Parlamentosu tarafından yayımlanan önerilere yapılan bir eklemedir (Figel, 2007; akt: Selçuk, 2016). Bu raporda anahtar yeterlikler; "anadilde iletişim", "yabancı dilde iletişim", "matematiksel yeterlik, fen ve teknolojide yeterlik", "dijital yeterlik", "öğrenmeyi öğrenme", "sosyal ve vatandaşl1k yeterlikleri”, "inisiyatif alma ve girişimcilik yeterliği" ve "kültürel farkındalık ve ifade etme yeterliği " olmak üzere sekiz ana başlıkta ele alınmaktadır (Avrupa Komisyonu, 2007). Küreselleşmenin ve bilgi toplumu olmanın bir getirisi olarak ortaya çıkan yaşam boyu öğrenme, beşikten mezara kadar öğrenmeyi temele alarak bireylerin yaşamları boyunca öğrenmeyi öğrenen bireyler olmalarını sağlamayı amaçlamaktadır.

Gerek 21.yy becerileri gerekse yaşam boyu öğrenme yeterlikleri dikkate alındığı okul bireylerin yaşam içerisinde kullanacakları gerekli bilgi, becerileri ve davranışların nasıl öğretmelidir? Özellikle sadece akademik başarı ölçütünün baskın olduğu eğitim sisteminde hangi yöntemler ile öğrenciler gerçek hayata hazırlanabilir? Önceki araştırmalar 21.yy'da çok yönlü başarı için en önemli yöntemin Proje Tabanlı Öğrenme (PTÖ) ortamının oluşturulması gerektiğini tavsiye etmektedir. Bell (2002)'e göre proje tabanlı öğrenmede öğrenciler sorgulayarak kendi öğrenmelerinden sorumlu olup, işbirlikli bir şekilde araştırma yapar ve kendi bilgilerini yansıtacakları projeler geliştirirler. Ayrıca PBL ile öğrenciler yeni ve uygulanabilir teknoloji becelerini geliştirirler, ileri düzey problmeleri çözebilir ve iletişim becerilerini artırırlar. Kokotsaki, Menzies ve Wiggins (2016) PTÖ öğrenme ortamı ile öğrencilerin kendi öğrenmelerini yönettiğini, yapıcı araştırmalar yaptıklarını, işbirliği ve iletişim becerilerini kullanarak gerçek dünya problemlerini becerilerini kullandıklarını savunmaktadır. Erdem (2002) PTÖ ortamının öğrencilerin kendi öğrenmelerini kurguladığı, yaratıcı düşünme, eleştisel düşünme, problemi işbirliği içerisinde çözme, teknolojiyi kullanma ve sosyal becerileri becerilerini uygulandığ ortam olduğunu savunmaktadır.

Özellikle okullarda PTÖ ortamının oluşmasında bilim fuarlarının yapılmasının rolü oldukça fazladır. Türkiye'de bilim fuarlarının 


\section{G. Selcuk-E.H. Atalmıs-A. Atac Ö̈̆gretmen ve Öğrencilere Göre 4006...}

desteklenmesinde Türkiye Bilimsel ve Teknolojik Araştırma Kurumu (TÜBİTAK) bünyesindeki Bilim ve Toplum Daire Başkanlığı etkisi oldukça fazladır. Özellikle bu birim bilimle toplumu tanıştırmak ve bilimsel okur yazarlı̆̆ artırmak için bilim fuarlarını "4006 Bilim fuarları Destekleme Programı" ile desteklemektedir. Bu program TÜBİTAK tarafından onaylanması halinde Milli Eğitim Bakanlığı'na bağlı ortaokul ve liselerde, Mesleki Eğitim Merkezlerin'de ve Bilim Sanat Merkezlerin'de düzenlenmektedir. 4006 bilim fuarları öğrencilere soru sorma ve problemi tanımlama becerisi, model oluşturma ve kullanma becerisi, araştırma planlama ve gerçekleştirme becerisi, veri analizi ve yorumlama becerisi, matematiksel ve bilgi-işlemsel düşünme becerisi, kanıtlardan argüman oluşturma becerisi ve bilgi iletişimi kurma becerisi kazandırılması hedeflenmektedir (TÜBİTAK, 2019a). TÜBİTAK bilgilendirme sunumuna göre Türkiye'de 2015 ile 2019 yilları arasında sirasıly 3428, 6341, 6078,10170 ve 6104 okul desteklenmiş ve bu proje ile 2018 y1lında 1686037 öğrenciye ulaşılmıştır (TÜBİTAK, 2019b).

Alan yazın incelendiğinde son zamanlarda 4006 bilim fuarları ile yapılan çalışmaların artığı ve bu çalışmaların çoğunun nitel araştırmalar olduğu görülmektedir. $\mathrm{Bu}$ çalışmalar incelendiğinde 4006 bilim fuarlarının öğrenci, öğretmen, okul ve velilere olumlu katkılar yaptığı görülmektedir. Öğrenciler açısından değerlendirildiğinde bilim fuarlarının öğrencinin derse kare karşı ilgi ve motivasyonun arttığı; kendini gerçekleştirdikleri; özgüvenler kazandıkları; problem çözme, yaratıcılık ve iletişim becerilerinin artırdığı; bilimsel düşünme ve araştırma becerileri kazandırdığı; derslerinde öğrendiklerin hayata uyarladıkları; sorumluluk, liderlik, kararlılık, yardımlaşma/işbirliği duygularını artırdıkları bulunmuştur (Atalmış, Selçuk ve Ataç, 2018; Avcı ve Özenir, 2018; Balc1, 2019; Benzer ve Evrensel, 2019; Çolakoğlu, 2018; Dede, 2019; Doğan, 2020; Okuyucu, 2019; Sontay, Anar ve Karamustafaoğlu, 2019; Soyuçak, 2018; Yıldırım, 2020). Öğretmenler açısından değerlendirildiğinde, 4006 bilim fuarlarının öğretmenlerin öğretimlerinde ve mesleki hayatlarında yenilenmeyi sağladığı; yaratıcı düşünme becerilerinin geliştiği, özgüvenlerin artığı, iş yaşam doyumlarının artığı, öğrencilerle iletişimlerin daha da kuvvetlendiği ve okula karş1 aidiyet duygularının arttığı bulunmuştur (Atalmış, Selçuk ve Ataç, 2018; Balc1, 2019; Dede, 2019; Doğan, 2020; Yıldırım, 2020). Okul açısından değerlendirildiğinde bu fuarlarla okulun çevrede tanıtımının yapılarak okulun imajının olumlu yönde arttığı, okuldaki eğitim-öğretimin niteliğinin artığı, okul bütçesinin artığ1, okul-öğretmen-öğrenci iletişimi artarak okul kültürünün oluşmaya başladığı bulunmuştur (Atalmış, Selçuk ve Ataç, 2018; Avcı ve Özenir, 2018). Veli açısından değerlendirildiğinde 4006 bilim fuarlarının öğrenci-veliöğretmen arasındaki iletişimi kuvvetlendirerek, velilerin okula karşı bakışlarını olumlu yönde değiştirmiştir (Atalmış, Selçuk ve Ataç, 2018; Doğan, 2020). 
Alan yazında az sayıdaki 4006 Bilim Fuarları ile yapılan nicel çalışmalara bakıldığında çoğunluğunun deneysel modelde desenlenmiş olduğu görülmektedir. Yapılan çalışamlarda bu projelerin öğrencilerin bilimsel süreç becerilerinin gelişmesini sağladığı (Keskin, 2019); öğrencilerin problem çözme becerilerinin artırdığı (Yıldırım, 2018); öğrencilerin fen dersine ve fen becerilerine yönelik algılarının, tutumlarının ve motivasyonlarının olumlu yönde değiştirdiği (Çavuş, Balçın ve Yılmaz, 2018; Durmaz, Dinçer ve Osmanoğlu, 2017; Keskin, 2019; Özdemir ve Babaoğlan, 2019); öğrencilerin bilim insanı imajını olumlu yönde etkilediği (Kahraman, 2019); ancak bilim fuarlarının öğrencilerin bilimsel epistemolojik inançlarını (Türkmen, 2019) ve akademik başarısını (Yıldırım, 2018) anlamlı bir şekilde değiştirmediği bulunmuştur (Türkmen, 2019). Keçeci, Zengin ve Alan (2018) ise yaptığı çalışmada bilim fuarlarının öğrenciler üzerine etkisinin bu fuarlarda görev alan öğretmen ve yöneticilerin yaklaşımlarına göre değişeceğini ileri sürmektedir.

Alan yazında 4006 bilim fuarlarına yönelik gerek nitel gerekse nicel çalışmalarının yanında, Bozdemir (2018) "TÜBİTAK bilim fuarı için yapılan projelerin öğrenci üzerindeki etkililiğinin değerlendirilmesi” isimli bir ölçek geliştirme çalışması yapmıştır. Çalışmada örneklem olarak 164 danışman öğretmen ve 18 proje yürütücü seçilerek onların algılarına göre bilim fuarlarının öğrenci üzerindeki etkilliği ölçülmüştür. Yapılan açımlayıcı faktör analizi sonucunda 46 maddeden oluşan 4 boyutlu bir beşli likert tipi bir ölçek elde edilmiştir. $\mathrm{Bu} 4$ boyut incelendiğinde 4006 bilim fuarlarının öğrencilerin "bilimsel düşünce", "özgüven", "grup dinamiği”, "liderlik” becerilerini ortaya çıkardığı görülmektedir. Bu boyutların bilim fuarlarınının öğrenciye katkılarına yönelik yapılan nitel çalışmalardaki elde edilen sonuçlarla örtüştüğü açıktır.

\section{Çalışmanın Önemi}

4006 bilim fuarlarına yönelik çalışmaların hızla arttığ 1 görülürken, sadece Bozdemir (2018) tarafından ölçek geliştirme çalışması olduğu görülmektedir. Bu ölçek çalışması detaylı bir şekilde incelendiğinde öğretmenlere göre bilim fuarlarının öğrenci üzerine etkililiği araştırılmıştır. Alan yazın incelendiğin bilim fuarlarının sadece öğrencilere değil, öğretmenlere, okullara ve velilere de etkililikleri söz konusudur. Bir de bu fuarların öğrenci üzerine etkililik düzeyleri sadece öğretmenler göre değil, öğrencilerin kendilerine de sorularak ölçülmesi gerekmektedir. Alan yazındaki bu açığı kapatmak için mevcut çalışmada öğretmen ve öğrencilere göre 4006 TÜBİTAK bilim fuarları etkililikleri ölçekleri geliştirilmiştir.

\section{YÖNTEM}




\section{G. Selcuk-E.H. Atalmıs-A. Atac Ö̈̆gretmen ve Öğrencilere Göre 4006...}

Ölçek geliştirme çalışması olan bu araştırmada öğrencilerin ve öğretmenlerin görüşlerine göre "4006 TÜBİTAK bilim fuarları etkililik Ölçekleri” geliştirilmiş ve bu süreçteki işlemler aşağıda açıklanmıştır.

\section{Çalışma Grubu}

Araştırmanın çalışma grubunu 2018-2019 eğitim öğretim yılında Kahramanmaraș ili Milli Eğitim Müdürlüğü (MEM)'ne bağlı okullarda farklı branşlarda görev yapan seçkisiz olarak belirlenen 348 öğretmen ve 367 öğrenciden oluşmaktadır. Öğretmenler demografik özellikleri incelendiğinde cinsiyet değişkenine göre 189'unun (\%54.5) erkek ve 158'inin (\%45.5) kadın; medeni durum değişkenine göre 103'ünün (\%29.7) bekar ve 244'ünün (\%70.3) evli; çalıştığı okul türü değişkenine göre 265'inin (\%76.4) ortaokul ve 82'sinin (\%23.6) lise görev yaptığı; öğretmenlerin yaş ortalamasının 33.4 ve hizmet yılı ortalamaları 8.9 yıl olduğu görülmektedir. Öğrenciler demografik özellikleri incelendiğinde cinsiyet değişkenine göre 154'ünün (\%42.0) erkek ve 213'ünün (\%58.0) kız; okul türü değişkenine göre 80'inin (\%21.8) lise ve 287’sinin(\%78.2) ortaokul; sınıf değişkenine göre 30'unun (\%8.2) 5.sınıf, 70'inin(\%19.1) 6.sınıf, 106'sinin (\%28.8) 7.sinif, 78'inin (\%21.3) 8.sinif, 18'inin (\%4.6) 9.sinif, 22'sinin (\%6.0) 10.sinıf ve 44'ünün (\%12.0) 11.sinıf olduğu görülmektedir.

\section{İşlem}

$\mathrm{Bu}$ araştırmada öncelikle geliştirilecek ölçeklerin kapsam geçerliğini sağlamak için 4006 TÜBİTAK, Bilim Fuarları ve Projeler ile ilgili ulusal veuluslararası alan yazın tarandıktan sonra bu projelerin öğretmenler ve öğrencilerine göre etkiliğine yönelik iki ayrı madde havuzu oluşturulmuştur. $\mathrm{Bu}$ bağlamda madde havuzunda "4006 TÜBİTAK bilim fuarları etkililiğine" ilişkin öğretmen görüşlerine göre 75 madde geliştirilirken öğrenci görüşlerine göre 43 madde geliştirilmiştir. Bu maddeler 2 eğitim programı uzmanı ve 3 ölçme ve değerlendirme uzmanı tarafından incelenmiş, öğretmen görüşlerine yönelik ölçeğin madde sayıs1 61'e ve öğrenci görüşlerine yönelik ölçeğin madde sayısı ile 35 'e düşürülmüsstür. Her iki ölçek formu 5'li likert tipinde hazırlanarak, ölçeklerde "1- kesinlikle katılmıyorum (1.00-1.80), 2 - katılmıyorum (1.812.60), 3 - k1smen kat1liyorum (2.61-3.40), 4 - kat1liyorum (3.41-4.20), 5 kesinlikle katıliyorum (4.21-5.00)" şeklinde tanımlanmıştır.

\section{Verilerin Analizi}

Ölçeklerin nihai formları öğretmenlere ve öğrencilere uygulandıktan sonra her iki ölçekte de ters madde yer almadığından tüm maddeler toplanarak toplam puanlar elde edilmiş ardından herbir maddenin ayırt edicilik indekslerini bulmak için madde-toplam korelasyonları hesaplanmıştır. Büyüköztürk (2018)'e göre bir 
maddenin ayırt edici olabilmesi için madde-toplam korelasyonun .30 ve daha yüksek olması gerektiğini ifade etmektedir.

Ayırt edici maddeler seçildikten sonra ölçeğin yapı geçerliliğini bulmak için çapraz geçerleme yöntemi uygulanmıştır. Bu süreçte veriler basit seçkisiz bir şekilde ikiye bölünüp, ilk kısmı ile açımlayıcı faktör analizi yapılırken diğer kısmı ile doğrulayıcı faktör analizi yapılmıştır. Bu çalışmada bu süreçler iki farklı ölçek için yapılacaktır.

Açımlayıcı faktör analizi SPSS 22.0 programı ile yapılarak, KaiserMeyerOlkin (KMO) katsayısı ve Barlett Sphericity testi sonuçları elde edilmiştir. Field (2009)'e göre bir verinin faktörleştirilebilir olması için Barlett Sphericity testinin anlamlı ve KMO değerinin .70'den büyük olması gerektiğini ifade etmektedir.

Doğrulayıcı faktör analizi için MPlus 7.0 programı kullanılmış ve model uyum indeks değerleri olan $\chi^{2}$ /sd, CFA, TLI, RMSEA ve SRMR hesaplanmıştır. Kline (2011)'a göre bir modelin kabul edilebilmesi için $\chi^{2} /$ sd değerinin 4 'ten küçük; CFI ve TLI değerlerinin .90 ve .90' dan büyük; RMSEA ve SRMR değerlerinin .08 ve .08 ' den küçük olması gerektiğini vurgulamaktadır. Son olarak ölçekler likert tipi olduklarından güvenirlikleri Croanbach Alpha iç tutarlılık katsayısı ile hesaplanacaktır. Psikolojik testler için güvenirlik katsayısının .70 ve daha yüksek olması test puanlarının yeterliliği için uygun görülmektedir (Büyüköztürk, 2018).

\section{BULGULAR}

$\mathrm{Bu}$ bölümde geliştiren iki ölçek için madde ayırt edicilik indeksi hesaplama, açımlayıcı faktör analizi, doğrulayıcı faktör analizi ve güvenirlik katsayısı hesaplama sonucundan elde edilen bulgular açıklanmaktadır.

\section{A. Öğrencilere Göre 4006 TÜBİTAK Bilim Fuarları Etkililik Ölçeği}

Madde Ayırt Edicilik Indeksi. Herbir maddenin ayırt edicilik indekslerini bulmak madde toplam korelasyon değerleri hesaplanarak sonuçlar Tablo 1'de gösterilmiştir. Maddelerin bu değerlerin incelendiğinde .30 (madde5) ile .67 (madde 12) arasında değiştiği görülürken, bu durum her bir maddenin ayırt edici olduğunu desteklemektedir.

Açımlayıcı Faktör Analizi (AFA). Uygulanan AFA sonucunda KMO değerinin .86 ve Barnett Testinin $(\mathrm{p}<.05)$ istatistiksel olarak anlamlı olduğu ortaya çıkmıştır. Ayrıca AFA sonucunda ölçeğin faktör sayısı 10 olarak bulunurken, bu faktörlerin ölçeğe ilişkin açıkladığ 1 varyans \%65.86 olarak el edilmiştir. Ölçeğin 1.faktörün özdeğeri (10.46) ile 2.faktörün özdeğeri (2.11) arasında keskin bir düşme olduğu görülmektedir. $\mathrm{Bu}$ faktörlerin açıklanan varyans oranları 


\section{G. Selcuk-E.H. Atalmıs-A. Atac Ö̈̆gretmen ve Öğrencilere Göre 4006...}

incelendiğinde sirasıyla \%29.90 ve \%6.03 olarak elde edilmiştir. Büyüköztürk (2018)'e göre, bir ölçeğin tek boyutlu olması için 1.faktöre ait özdeğerin 2.faktöre ait özdeğerine oranının 3 'den büyük olmasıdır. Bu çalışmada bu oran yaklaşık 5 kat (29.90/6.03) olduğundan, 35 maddelik "Öğrencilere göre 4006 TÜBİTAK Bilim Fuarları Etkililik Ölçeği”" tek boyutlu olarak düşünülmektedir. Tablo 1'de her bir maddenin faktör yükleri gösterilmiştir.

Tablo 1. Maddelerin Madde-Toplam Korelasyonu (MTK) ve Faktör Yükleri (FK)

\begin{tabular}{lcc|lcc|lcc}
\hline Madde & MTK & FK & Madde & MTK & FK & Madde & MTK & FK \\
\hline S1 & .57 & .57 & S13 & .54 & .55 & S25 & .57 & .58 \\
S2 & .48 & .50 & S14 & .54 & .55 & S26 & .60 & .61 \\
S3 & .33 & .43 & S15 & .57 & .56 & S27 & .54 & .56 \\
S4 & .44 & .46 & S16 & .64 & .65 & S28 & .57 & .57 \\
S5 & .30 & .52 & S17 & .56 & .57 & S29 & .61 & .61 \\
S6 & .47 & .48 & S18 & .51 & .52 & S30 & .55 & .56 \\
S7 & .47 & .48 & S19 & .54 & .55 & S31 & .61 & .61 \\
S8 & .50 & .48 & S20 & .63 & .61 & S32 & .56 & .56 \\
S9 & .55 & .54 & S21 & .64 & .62 & S33 & .66 & .67 \\
S10 & .48 & .47 & S22 & .58 & .57 & S34 & .49 & .48 \\
S11 & .58 & .59 & S23 & .54 & .52 & S35 & .35 & .41 \\
S12 & .67 & .68 & S24 & .64 & .63 & & & \\
\hline
\end{tabular}

Doğrulayıcı Faktör Analizi (DFA). AFA sonucunda elde edilen tek faktörlü ölçeği doğrulamak için örneklemin diğer kısmı (n=184) kullanılarak Mplus 7.4 programında DFA yapılmıştır. Elde edilen DFA modeli Şekil 1'de gösterilmiştir. Modelin uyum indeksleri incelendiğinde $\chi 2$ /sd değerinin 4 'ten küçük; CFI/ TLI değerlerinin .90' dan büyük; RMSEA/SRMR değerlerinin .08 den küçük olduğu görülerek modelin kabul edilebilir düzeyde olduğunu bulunmuştur $(\chi 2(506,159)$ $=657.27 ; \mathrm{CFI}=.91 ; \mathrm{TLI}=.90 ; \mathrm{RMSEA}=.04 ; \mathrm{SRMR}=.06)$.

Güvenirlik Katsaylsı hesaplama. Ölçeğin güvenirliği gösteren Croanbach Alpha iç tutarlılık katsayısı .93 olarak bulunarak, ölçeğin güvenilir olduğunu gösterilmiştir.

Tablo 2'de ayrıca ölçek ve ölçek maddelerinin ortalama ve standart sapması gösterilmektedir.

Tablo 2. Madde Ortalamaları ve Standart Sapması

$\begin{array}{llllllllll}\text { Madde } & X & \text { SS } & \text { Madde } & X & \text { SS } & \text { Madde } & X & \text { SS }\end{array}$




\begin{tabular}{ccc|ccc|ccc}
\cline { 6 - 7 } S1 & 4.34 & .94 & $\mathrm{~S} 13$ & 4.37 & .93 & $\mathrm{~S} 25$ & 4.19 & 1.05 \\
S2 & 4.46 & .78 & $\mathrm{~S} 14$ & 4.34 & .90 & $\mathrm{~S} 26$ & 3.97 & 1.14 \\
S3 & 4.47 & .79 & $\mathrm{~S} 15$ & 3.95 & 1.21 & $\mathrm{~S} 27$ & 4.30 & .98 \\
$\mathrm{~S} 4$ & 4.44 & .81 & $\mathrm{~S} 16$ & 4.05 & 1.12 & $\mathrm{~S} 28$ & 4.17 & 1.08 \\
S5 & 4.39 & .89 & $\mathrm{~S} 17$ & 4.36 & .90 & $\mathrm{~S} 29$ & 4.01 & 1.11 \\
S6 & 4.30 & .98 & $\mathrm{~S} 18$ & 4.45 & .87 & $\mathrm{~S} 30$ & 4.39 & .98 \\
S7 & 4.35 & .86 & $\mathrm{~S} 19$ & 4.13 & .99 & $\mathrm{~S} 31$ & 4.04 & 1.09 \\
S8 & 4.26 & 1.03 & $\mathrm{~S} 20$ & 3.68 & 1.44 & $\mathrm{~S} 32$ & 4.26 & 1.06 \\
S9 & 3.85 & 1.17 & $\mathrm{~S} 21$ & 3.16 & 1.51 & $\mathrm{~S} 33$ & 4.18 & 1.01 \\
S10 & 4.20 & 1.04 & $\mathrm{~S} 22$ & 4.32 & 1.01 & $\mathrm{~S} 34$ & 4.13 & 1.03 \\
S11 & 4.24 & .96 & $\mathrm{~S} 23$ & 4.04 & 1.21 & $\mathrm{~S} 35$ & 4.09 & 1.29 \\
S12 & 4.29 & .97 & $\mathrm{~S} 24$ & 4.00 & 1.28 & & & \\
\hline Ölçeğin bütünüi & 4.19 & .56 & & & & & & \\
\hline
\end{tabular}

Tablo 2'e göre maddelerin ortalamalarının 3.16 (madde 21) ile 4.46 (madde 2) arasında olduğu görülmektedir. Bu durum maddelerin "Kısmen Katılıyorum" ile "Tamamen katılıyorum" aralığına düştüğü göstermektedir. Ölçeğin tümü için ise ortalamanın 4.19 olduğu hesaplanmış ve bu durumun "Katılıyorum" aralığına düşmektedir.

\section{B. Öğretmenlere Göre 4006 TÜBİTAK Bilim Fuarları Etkililik Ölçeği}

Madde Ayırt Edicilik Indeksi. Herbir maddenin ayırt edicilik indekslerini bulmak madde toplam korelasyon değerleri hesaplanarak sonuçlar Tablo 3'de gösterilmiştir. Maddelerin bu değerlerin incelendiğinde 0.37 (madde6) ile 0.91 (madde 34) arasında değiştiği görülürken, bu durum her bir maddenin ayırt edici olduğunu desteklemektedir.

Açımlayıcı Faktör Analizi (AFA). Uygulanan AFA sonucunda KMO değerinin .95 ve Barnett Testinin $(\mathrm{p}<.05)$ istatistiksel olarak anlamlı olduğu ortaya çıkmıştır. Ayrıca AFA sonucunda birden fazla faktörde değer alan veya hiçbir faktöre bağlanmayan toplam 15 madde faktörden çıkarılarak 46 maddelik 3 faktörlü "Öğretmenlere Göre 4006 TÜBİTAK Bilim Fuarları Etkililik Ölçeği" elde edilmiştir (Öğrenciye katk1 (F1), öğretmene katk1 (F2) ve veliye katk1 (F3)). Her bir faktörun açıkladığı varyans oranları sırasıyla \%39.41, \%26.13 ve \%20.25 olmak üzere toplam açılana varyans oranı \%85.79'dur. Tablo 3 'de her bir maddenin faktör yükleri ve bağlandığı faktörler gösterilmiştir.

Tablo 3. Maddelerin Madde-Toplam Korelasyonu (MTK) ve Faktör Yükleri (FK) 
G. Selcuk-E.H. Atalmıs-A. Atac Ö̈ğretmen ve Öğrencilere Göre 4006...

\begin{tabular}{|c|c|c|c|c|c|c|c|c|}
\hline $\mathbf{M}$ & MTK & FK & $\mathbf{M}$ & MTK & FK & $\mathbf{M}$ & MTK & FK \\
\hline S1 & .82 & - & S22 & .87 & $\begin{array}{r}.83 \\
\text { (F1) }\end{array}$ & $\begin{array}{l}\text { S4 } \\
3\end{array}$ & .86 & - \\
\hline S2 & .82 & - & S23 & .86 & $\begin{array}{r}.83 \\
\text { (F1) }\end{array}$ & $\begin{array}{l}\text { S4 } \\
4\end{array}$ & .82 & - \\
\hline S3 & .82 & - & S24 & .87 & $\begin{array}{r}.82 \\
\text { (F1) }\end{array}$ & $\begin{array}{l}\text { S4 } \\
5\end{array}$ & .87 & - \\
\hline S4 & .80 & - & S25 & .88 & $\begin{array}{r}.85 \\
\text { (F1) }\end{array}$ & $\begin{array}{l}\text { S4 } \\
6\end{array}$ & .87 & $.68(\mathrm{~F} 2)$ \\
\hline S5 & .86 & - & S26 & .89 & $\begin{array}{r}.84 \\
\text { (F1) }\end{array}$ & $\begin{array}{l}\text { S4 } \\
7\end{array}$ & .82 & $.79(\mathrm{~F} 2)$ \\
\hline S6 & .37 & - & S27 & .89 & $\begin{array}{r}.84 \\
\text { (F1) }\end{array}$ & $\begin{array}{l}\text { S4 } \\
8\end{array}$ & .86 & $.76(\mathrm{~F} 2)$ \\
\hline S7 & .75 & - & S28 & .88 & $\begin{array}{r}.86 \\
(\mathrm{~F} 1)\end{array}$ & $\begin{array}{l}\text { S4 } \\
9\end{array}$ & .87 & - \\
\hline S8 & .75 & - & S29 & .87 & $\begin{array}{r}.82 \\
\text { (F1) }\end{array}$ & $\begin{array}{l}\text { S5 } \\
0\end{array}$ & .88 & $.74(\mathrm{~F} 2)$ \\
\hline S9 & .86 & - & S30 & .90 & $\begin{array}{r}.82 \\
\text { (F1) }\end{array}$ & $\begin{array}{l}\text { S5 } \\
1\end{array}$ & .89 & $.75(\mathrm{~F} 2)$ \\
\hline S10 & .84 & - & S31 & .88 & $\begin{array}{r}.85 \\
\text { (F1) }\end{array}$ & $\begin{array}{l}\text { S5 } \\
2\end{array}$ & .84 & .79 (F2) \\
\hline S11 & .75 & .78 (F3) & S32 & .84 & $\begin{array}{r}.77 \\
\text { (F1) }\end{array}$ & $\begin{array}{l}\text { S5 } \\
3\end{array}$ & .87 & $.70(\mathrm{~F} 2)$ \\
\hline S12 & .74 & $.85(\mathrm{~F} 3)$ & S33 & .88 & $\begin{array}{r}.79 \\
(\mathrm{~F} 1)\end{array}$ & $\begin{array}{l}\text { S5 } \\
4\end{array}$ & .82 & $.76(\mathrm{~F} 2)$ \\
\hline S13 & .70 & .89 (F3) & S34 & .91 & $\begin{array}{r}.82 \\
\text { (F1) }\end{array}$ & $\begin{array}{l}\text { S5 } \\
5\end{array}$ & .84 & $.71(\mathrm{~F} 2)$ \\
\hline S14 & .74 & $.84(\mathrm{~F} 3)$ & S35 & .85 & $\begin{array}{r}.81 \\
\text { (F1) }\end{array}$ & $\begin{array}{l}\text { S5 } \\
6\end{array}$ & .86 & $.78(\mathrm{~F} 2)$ \\
\hline S15 & .67 & .90 (F3) & S36 & .85 & $\begin{array}{r}.78 \\
\text { (F1) }\end{array}$ & $\begin{array}{l}\text { S5 } \\
7\end{array}$ & .89 & (1) \\
\hline S16 & .71 & .90 (F3) & S37 & .89 & $\begin{array}{r}.83(\mathrm{~F} 1 \\
)\end{array}$ & $\begin{array}{l}\text { S5 } \\
8\end{array}$ & .81 & $.77(\mathrm{~F} 2)$ \\
\hline S17 & .74 & $.84(\mathrm{~F} 3)$ & S38 & .89 & $\begin{array}{r}.82 \\
(\mathrm{~F} 1)\end{array}$ & $\begin{array}{l}\text { S5 } \\
9\end{array}$ & .79 & $.76(\mathrm{~F} 2)$ \\
\hline S18 & .70 & $.86(\mathrm{~F} 3)$ & S39 & .85 & $\begin{array}{r}.71 \\
\text { (F1) }\end{array}$ & $\begin{array}{l}\text { S6 } \\
0\end{array}$ & .81 & .79 (F2) \\
\hline S19 & .73 & .67 (F3) & S40 & .88 & $\begin{array}{r}.82 \\
\text { (F1) }\end{array}$ & $\begin{array}{l}\text { S6 } \\
1\end{array}$ & .86 & $.79(\mathrm{~F} 2)$ \\
\hline S20 & .89 & $.83(\mathrm{~F} 1)$ & S41 & .89 & $\begin{array}{r}.72 \\
\text { (F1) }\end{array}$ & & & \\
\hline
\end{tabular}


S21

$$
\begin{array}{ll|llr}
.87 & .83(\mathrm{~F} 1) & \mathrm{S} 42 & .77 & .60 \\
& & .77 & (\mathrm{~F} 2)
\end{array}
$$

- işaretli maddeler ölçekten çıkarılan maddelerdir

Doğrulayıcı Faktör Analizi (DFA). AFA sonucunda elde edilen 3 faktörlü ölçeği doğrulamak için örneklemin diğer kısmı (n=173) kullanılarak Mplus 7.4 programında DFA yapılmıştır. Elde edilen DFA modeli Şekil 2'de gösterilmiştir. Modelin uyum indeksleri incelendiğinde $\chi 2$ /sd değerinin 4 'ten küçük; CFI/ TLI değerlerinin .90' dan büyük; RMSEA/SRMR değerlerinin .08 den küçük olduğu görülerek modelin kabul edilebilir düzeyde olduğunu bulunmuştur $(\chi 2(923,173)$ $=$ 2124.76; CFI = .91; TLI = .90; RMSEA = .07; SRMR = .06).

Güvenirlik Katsaylsı hesaplama. Ölçeğin güvenirliği gösteren Croanbach Alpha iç tutarlılık katsayısı .99 olarak bulunarak, ölçeğin güvenilir olduğunu gösterilmiştir. Faktör bazında incelendiğinde öğrenciye katk1 (F1), öğretmene katk1 (F2) ve veliye katk1 (F3) faktörlerinin sırasıyla iç tutarlılık katsayıları .99, .98 ve .98 olarak bulunmuştur.

Tablo 4’te ayrıca ölçek ve ölçek maddelerinin ortalama ve standart sapması gösterilmektedir.

Tablo 4. Madde Ortalamaları ve Standart Sapması

\begin{tabular}{ccc|ccc|ccc}
\hline Madde & $\mathbf{X}$ & \multicolumn{1}{c}{ SS } & Madde & $\mathbf{X}$ & \multicolumn{1}{c}{ SS } & Madde & $\mathbf{X}$ & SS \\
\hline M1 & 4.16 & .94 & M17 & 4.58 & .72 & M33 & 4.51 & .80 \\
M2 & 3.95 & 1.02 & M18 & 4.56 & .74 & M34 & 4.43 & .90 \\
M3 & 3.91 & 1.08 & M19 & 4.50 & .79 & M35 & 4.34 & .89 \\
M4 & 3.99 & 1.04 & M20 & 4.56 & .71 & M36 & 4.43 & .84 \\
M5 & 3.84 & 1.16 & M21 & 4.52 & .75 & M37 & 4.47 & .87 \\
M6 & 3.83 & 1.13 & M22 & 4.46 & .80 & M38 & 4.48 & .85 \\
M7 & 3.94 & 1.05 & M23 & 4.59 & .68 & M39 & 4.45 & .89 \\
M8 & 3.85 & 1.17 & M24 & 4.51 & .73 & M40 & 4.46 & .86 \\
M9 & 4.30 & 1.93 & M25 & 4.56 & .71 & M41 & 4.23 & 1.04 \\
M10 & 4.52 & .76 & M26 & 4.29 & .94 & M42 & 4.40 & .85 \\
M11 & 4.55 & .72 & M27 & 4.52 & .72 & M43 & 4.58 & .73 \\
M12 & 4.56 & .74 & M28 & 4.37 & .85 & M44 & 4.53 & .78 \\
M13 & 4.70 & .60 & M29 & 4.34 & .90 & M45 & 4.45 & .85 \\
M14 & 4.54 & .75 & M30 & 4.49 & .76 & M46 & 4.51 & .77 \\
M15 & 4.56 & .68 & M31 & 4.42 & .88 & & & \\
M16 & 4.53 & .71 & M32 & 4.36 & .83 & & & \\
\hline
\end{tabular}


G. Selcuk-E.H. Atalmıs-A. Atac Öğretmen ve Öğgrencilere Göre 4006...

\begin{tabular}{ccc}
\hline Öğrenciye katkı & 4.51 & .66 \\
\hline Öğretmene katkı & 4.45 & .75 \\
\hline Veliye katkı & 3.98 & .96 \\
\hline Ölçeğin bütünüi & 4.38 & .67 \\
\hline
\end{tabular}

Tablo 4'e göre maddelerin ortalamalarının 4.70 (M13) ile 3.83 (M6) arasında olduğu görülmektedir. Bu durum maddelerin "Katılıyorum" ile "Tamamen katıllyorum" aralığına düştüğü göstermektedir. Ölçeğin tümü için ise ortalamanın 4.38 olduğu hesaplanmış ve bu durumun "Tamamen Katılıyorum" aralığına düşmektedir. Ölçeğin alt boyutları olan öğrenciye katk1, öğretmen katkı ve veliye katkı boyutları ortalaması sırasıly $4.51,4.45$ ve 3.98 olduğu hesaplanmıştır. $\mathrm{Bu}$ durum öğrenci ve öğretmene katkı boyutlarının "Tamamen Katılıyorum" aralığına düşerken, veliye katkı boyutunun ise "Katılıyorum" aralığına düştüğünü göstermektedir. 


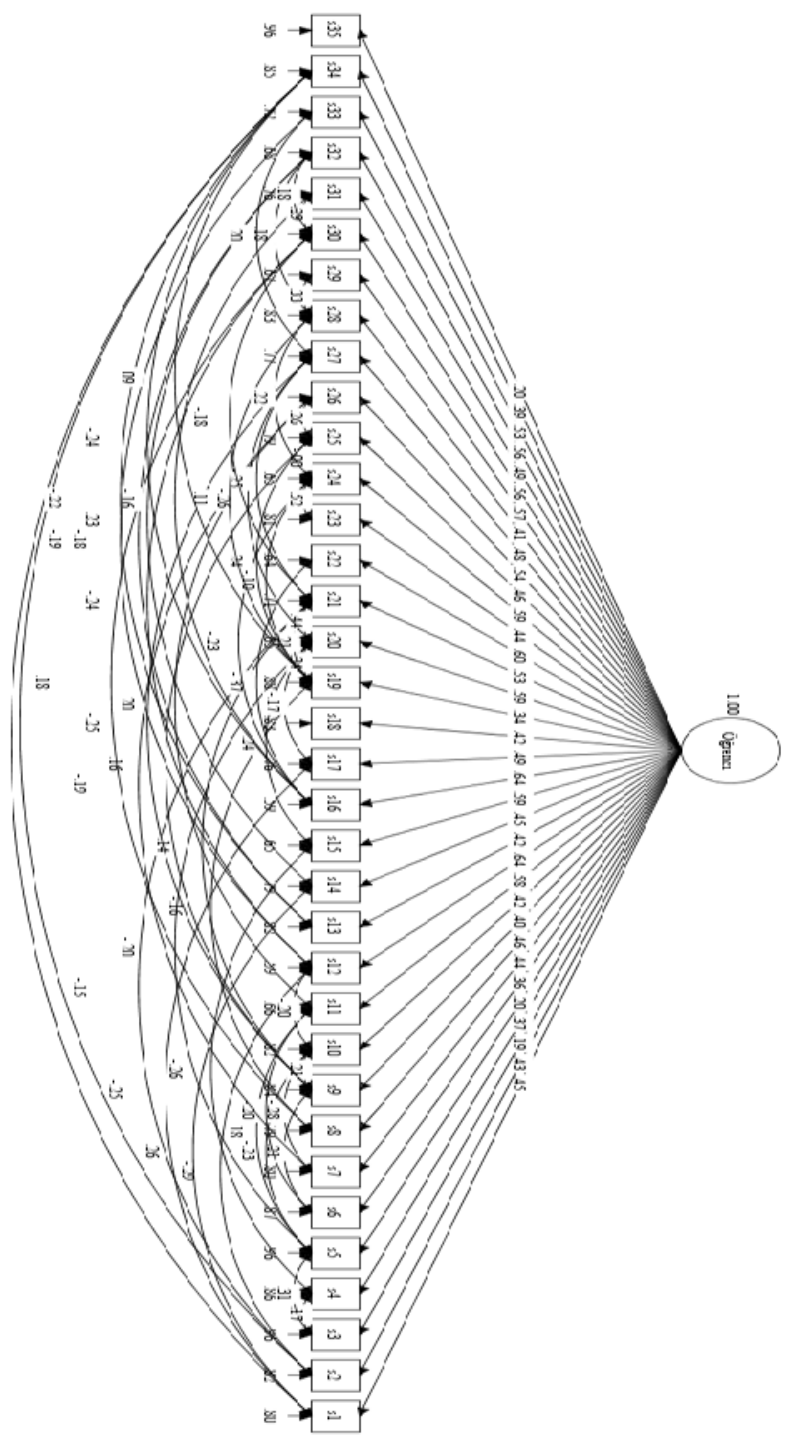

Şekil 1. "Öğrencilere Göre 4006 TÜBITAK Bilim Fuarları Etkililik Ölçeği” Doğrulayıcı Faktör Analizi Diyagramı 
G. Selcuk-E.H. Atalmıs-A. Atac Ö̆ğretmen ve Öğrencilere Göre 4006...

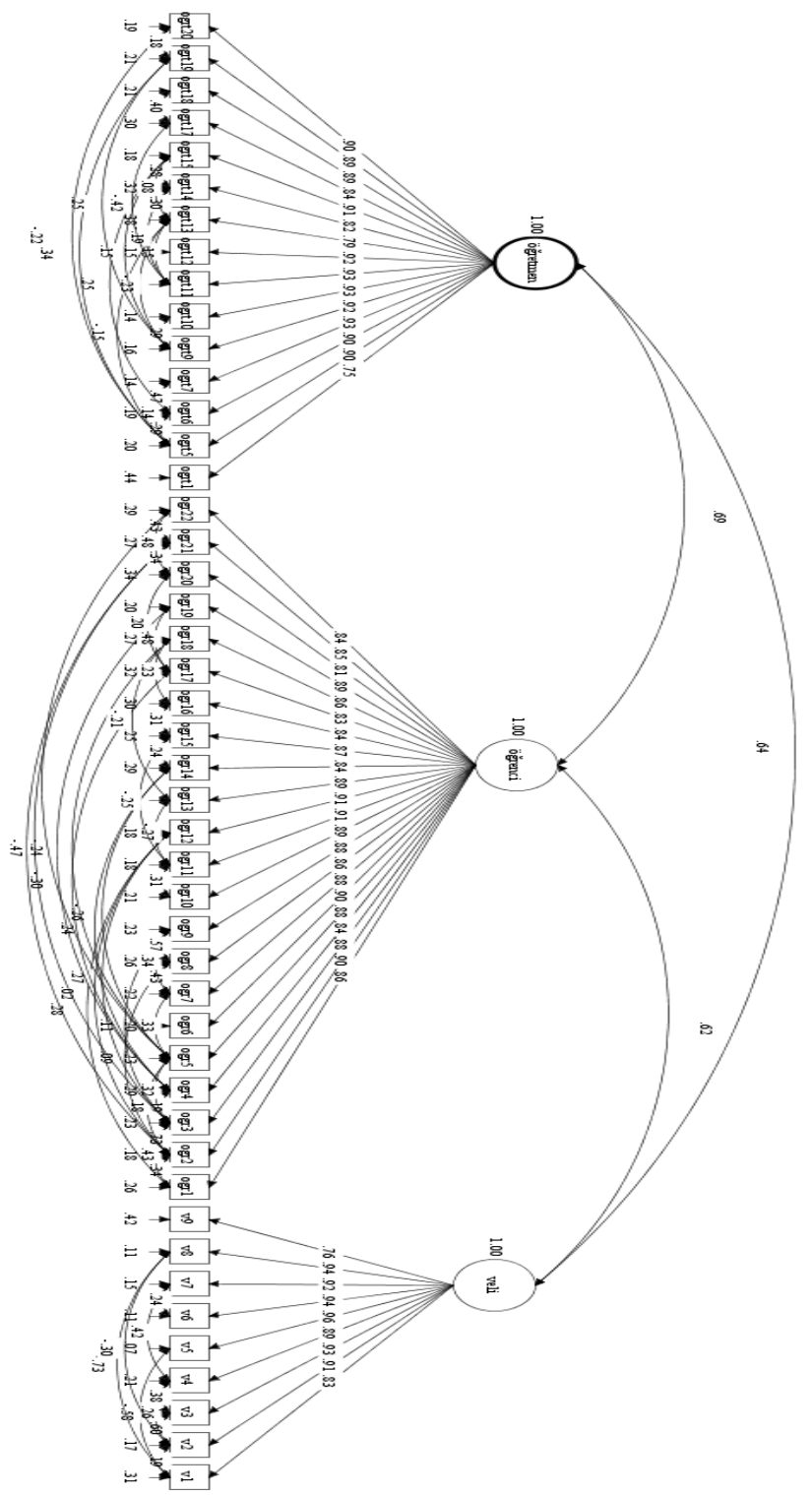

Şekil 2. "Öğretmenler Göre 4006 TÜBITAK Bilim Fuarları Etkililik Ölçeği”Dğrulayıcı Faktör Analizi Diyagramı

\section{SONUÇ VE TARTIŞMA}

Bu çalışmada, öğretmen ve öğrencilerin 4006 TÜBİTAK Bilim Fuarlarına yönelik görüşlerini belirlemek üzere “Öğretmen ve Öğrencilere Göre 4006 
Tübitak Bilim Fuarlari Etkililikleri Ölçekleri”nin geliştirilmesi amaçlanmıştır. Araştırmada öncelikle geliştirilecek ölçeklerin kapsam geçerliğini sağlamak için 4006 TÜBİTAK Bilim Fuarları ve projeler ile ilgili ulusal ve uluslararası alan yazın tarandıktan sonra bu projelerin öğretmenler ve öğrencilerine göre etkiliğgine yönelik iki ayrı madde havuzu oluşturulmuştur. Bu bağlamda madde havuzunda "4006 TÜBİTAK bilim fuarları etkililiğine" ilişkin öğretmen görüşlerine göre 75 madde geliştirilirken öğrenci görüşlerine göre 43 madde geliştirilmiştir. Ardından bu maddeler alanında uzmanlar tarafından incelenmiş, öğretmen görüşlerine yönelik ölçeğin madde sayısı 61'e ve öğrenci görüşlerine yönelik ölçeğin madde sayıs1 ile 35'e düşürülmüştür. Her iki ölçek formu da 5'li likert şeklinde tanımlanmıştır. Daha sonra ölçeğin nihai formu Kahramanmaraş ili MEM'ne bağlı okullarda görev yapan 348 öğretmen ve 367 öğrenciye uygulanmıştır.

Ölçeklerin nihai formları öğretmenlere ve öğrencilere uygulandıktan sonra her iki ölçekte de ters madde yer almadığından tüm maddeler toplanarak toplam puanlar elde edilmiş ardından herbir maddenin ayırt edicilik indekslerini bulmak için madde-toplam korelasyonları hesaplanmıştır.

“Öğrencilere Göre 4006 TÜBİTAK Bilim Fuarları Etkililik Ölçeği”nde yer alan maddelerin herbirinin ayırt edicilik indeksi .30 ve daha yüksek olması nedeniyle ölçekten hiçbir madde dışarıda bırakılmamıştır. Ayırt edici maddeler seçildikten sonra ölçeğin yapı geçerliliğini bulmak için çapraz geçerleme yöntemi uygulanmıştır. $\mathrm{Bu}$ süreçte veriler basit seçkisiz bir şekilde ikiye bölünüp, ilk kısmı ile AFA yapılırken diğer kısmı ile DFA yapılmıştır. AFA sonucunda KMO değerinin .86 ve Barnett Testinin $(\mathrm{p}<.05)$ istatistiksel olarak anlamlı olmas1, verinin AFA'nın yapılmasına uygun olduğunu desteklemiştir. AFA sonucunda ölçeğin faktör sayıs1 10 olarak bulunurken, bu faktörlerin ölçeğe ilişkin açıkladığ 1 varyans \%65.86 olarak elde edilmiştir. Bu ölçekte ilk faktörün açıkladığı varyans ile ikinci faktörün açıkladığı varyans oran 3 kattan fazla olduğundan 35 maddelik “Öğrencilere göre 4006 TÜBİTAK Bilim Fuarları Etkililik Ölçeği” tek boyutlu model olarak kabul edilmiştir. Bu modeli doğrulamak amacıyla örneklemin ikinci kısmı ile DFA yapılmıştır. DFA sonucunda model uyum indekslerinin "kabul edilebilir” düzeyde olduğu bulunarak ölçeğin yapı geçerliği sağlanmıştır. Ölçeğin güvenirliği ise Croanbach Alpha katsayısı ile hesaplanmış ve .93 bulunmuştur.

İkinci olarak geliştirilen “Öğretmenlere Göre 4006 TÜBİTAK Bilim Fuarları Etkililik Ölçeği”nde yer alan maddelerin herbirinin ayırt edicilik indeksi .30 ve daha yüksek olması nedeniyle ölçekten hiçbir madde dışarıda bırakılmamıştır. Uygulanan AFA sonucunda KMO değerinin .95 ve Barnett Testinin $(p<.05)$ istatistiksel olarak anlamlı olduğu ortaya çıkmıştır. Ayrıca AFA sonucunda birden fazla faktörde değer alan veya hiçbir faktöre bağlanmayan toplam 15 madde faktörden çıkarılarak 46 maddelik 3 faktörlü "Öğretmenlere Göre 4006 TÜBİTAK Bilim Fuarları Etkililik Ölçeği” elde edilmiştir. Toplam açıklanan 
G. Selcuk-E.H. Atalmıs-A. Atac Ö̆ğretmen ve Öğrencilere Göre 4006...

varyans oran1 \%85.79'dur. Üç faktörlü bu modeli doğrulamak amaciyla örneklemin ikinci kısmı ile DFA yapılmıştır. DFA sonucunda model uyum indekslerinin "kabul edilebilir" düzeyde olduğu bulunarak ölçeğin yapı geçerliği sağlanmıştır. Ölçeğin güvenirliği ise Croanbach Alpha katsayısı ile hesaplanmış ve .99 bulunmuştur.Faktör bazında incelendiğinde öğrenciye katk1 (F1), öğretmene katk1 (F2) ve veliye katk1 (F3) faktörlerinin sirasıyla iç tutarlılık katsayıları $.99, .98$ ve .98 olarak bulunmuştur. Bu sonuçlar da ölçeğin güvenilir olduğunu göstermektedir.

Elde edilen sonuçlar, mevcut çalışmadaki "Öğretmen ve Öğrencilere Göre 4006 Tübitak Bilim Fuarlari Etkililikleri Ölçekleri” nin hem geçerli hem de güvenilir olduğunu destekler niteliktedir. $\mathrm{Bu}$ ölçekler kullanılarak gerçekleştirilecek çalışma sonuçlarının hem Tübitak 4006 projelerinin daha etkili ve verimli bir şekilde planlanması sürecine hem de alan yazına büyük ölçüde katkı sağlayacağı düşünülmektedir.

\section{KAYNAKÇA}

Atalmış, Erkan Hasan; Selçuk, Gülenaz ve Ataç, Ahmet (2018), “TUBİTAK 4006 Projelerine İlişkin Yönetici, Yürütücü ve Öğrenci Görüşleri”, Kırşehir Eğitim Fakültesi Dergisi, 19(3), ss. 1999-2020.

Avcı, Esat ve Özenir, Özgül Su (2018), “Bilim Fuarları Sürecinin Yürütücü Öğretmenler Gözünden Değerlendirilmesi”, Elementary Education Online, 17(3), ss. 1672-1690.

Avrupa Komisyonu (2007), What is LifeLong Learning? Avrupa

Komisyonu",

http://ec.europa.eu/education/policies/lll/life/what_islll_en.html

Nisan 2019 tarihinde erişildi.

Balcı, Ebru (2019), TÜBİTAK 4006 Bilim Fuarlarının Değerlendirilmesi: Polatlı Örneği, Yayınlanmamış Yüksek Lisans Tezi, Bolu Abant İzzet Baysal Üniversitesi, Eğitim Bilimleri Enstitüsü, Bolu.

Bell, Stephanie (2010), "Project-Based Learning for the 21st Century: Skills for the Future”, The Clearing House, 83(2), ss. 39-43.

Benzer, Semra ve Evrensel, Esra (2019), “TÜBİTAK 4006 Bilim Fuarı Hakkında Öğrenci Görüşleri”, Journal of Steam Education, 2(2), ss. 28-38.

Bozdemir, Erhan (2018), TÜBíTAK Bilim Fuarlarında Yapılan Projelerin Öğrenciler Üzerindeki Etkililiğinin Değerlendirilmesi, 
Yayınlanmamış Yüksek Lisans Tezi, Çanakkale Onsekiz Mart Üniversitesi, Eğitim Bilimleri Enstitüsü, Çanakkale.

Çavuş, Ragıp; Balçın, Muhammed Doğukan ve Yılmaz, Muhammet Mustafa (2018), "Bilim Fuarı Etkinliklerinin Ortaokul Öğrencilerinin Fen ve Problem Çözme Becerilerine Yönelik Algılarına Etkisi”, İnönü Üniversitesi Eğitim Bilimleri Enstitüsü Dergisi, 5(10), ss. 1-17.

Çolakoğlu, Mustafa Hilmi (2018), “TUBİTAK 4006 Bilim Fuarları Desteğinin Ĕgitim ve Öğretime Katkısı”, Journal of STEAM Education, 1(1), ss. 48-63.

Dede, Ayşegül (2019), TÜBİTAK 4006 Bilim Fuarlarının Fen Bilimleri Öğretmenleri Açısından Değerlendirilmesi, Yayınlanmamış Yüksek Lisans Tezi, Recep Tayyip Erdoğan Üniversitesi, Fen Bilimleri Enstitüsü, Rize.

Dogan, Soner (2020), "Do TUBITAK-4006 Science Fairs Achieve Its Objectives? The Viewpoints of School Administrators and Teachers”, International Journal of Progressive Education, 16(2), ss. 2641.

Durmaz, Hüsnüye; Dinçer, Emrah Oğuzhan ve Osmanoğlu, Aslıhan (2017), "Bilim Şenliğinin Öğretmen Adaylarının Fen Öğretimine ve Öğrencilerin Fene Yönelik Tutumlarına Etkisi”, Trakya Üniversitesi Eğitim Fakültesi Dergisi, 7(2), ss. 364-378.

Erdem, Mukaddes (2002), “Proje Tabanlı Öğrenme”, Hacettepe Üniversitesi Eğitim Fakültesi Dergisi, 22, ss. 172 -179.

Figel, Jan (2007), Key Competences for Lifelong Learning-European Reference Framework, Luxembourg: Office for Official Publicatios of the European Communities.

Kahraman, Ümmügülsüm (2019), TÜBİTAK 4006 Bilim Fuarlarının Öğrencilerin Bilim İnsanı İmajına Etkisi Ağrı İli Örneği, Yayınlanmamış Yüksek Lisans Tezi, Ağrı İbrahim Çeçen Üniversitesi, Fen Bilimleri Enstitüsü, Ağrı.

Keçeci, Gonca- Zengin, Fikriye Kurbağ ve Alan, Burcu (2018), “Comparing the Science Festival Attitudes of Students Participating As Observers in School Science Fairs”, Acta Didactica Napocensia, 11, ss. 175-183.

Keskin, Durdu (2019), Bilim Fuarlarının Ortaokul Öğrencilerinin Bilimsel Süreç Becerileri, Fen Dersine Karşı Motivasyonları ve Kaygı 
G. Selcuk-E.H. Atalmıs-A. Atac Öğretmen ve Öğrencilere Göre 4006...

Düzeyleri Üzerinde Etkisi, Yayınlanmamış Yüksek Lisans Tezi, Pamukkale Üniversitesi, Eğitim Bilimleri Enstitüsü, Denizli.

Kokotsaki, Dimitra; Menzies, Victoria ve Wiggins, Andy (2016), "Project-

Based Learning: A Review of the Literature", Improving Schools, 19(3), ss. 267-277.

Okuyucu, Mehmet Ata (2015), “4006-TÜBİTAK Bilim Fuarına İlişkin Öğretmen ve Öğrenci Görüşleri”, International Journal of Social Sciences and Education Research, 5(2), ss. 202-218.

Özdemir, Burcu Babaoğlan ve Babaoğlan, Başak (2019), “TÜBíTAK 4006 Bilim Fuarlarının 6. Sınıf Öğrencilerinin Bilimsel Süreç Becerileri ve Fen Bilimleri Dersine Yönelik Tutumlarıyla İlişkisi”, İnformal Ortamlarda Araştırmalar Dergisi, 4(1), ss. 22-36.

Partnership for 21st Century Skills (2015), P21 Framework Definitions, Retrieved from:

http://www.p21.org/storage/documents/docs/P21 Framework Definitio ns New Logo_2015.pdf

Selçuk, Gülenaz (2016), “Öğretmen Adaylarının Yaşam Boyu Öğrenme Yeterlik Algıları ve Öz-Yeterlik İnançlarının Öğretmen Yetiştirme Programı Kapsamında İncelenmesi”, Yayınlanmamış Doktora Tezi, Yakın Doğu Üniversitesi, Eğitim Bilimleri Enstitüsü, KKTC.

Sontay, Gökhan; Anar, Fatih ve Karamustafaoğlu, Orhan (2019), “4006TÜBITTAK Bilim Fuarı'na Katılan Ortaokul Öğrencilerinin Bilim Fuarı Hakkındaki Görüşleri”, International e-Journal of Educational Studies, 3(5), 16-28.

Soyuçok, Hamza (2018), TÜBİTAK 4006 Bilim Fuarları Kapsamında Hazırlanan Fen Projeleri Hakkında Çalışmalara Katılan Farklı Kesimlerin Görüşleri, Yayınlanmamış Yüksek Lisans Tezi, Ağrı İbrahim Çeçen Üniversitesi, Fen Bilimleri Enstitüsü, Ağrı.

TÜBİTAK (2019a), 4006 Bilim Fuarları Kılavuzu, Erişim adresi: https://www.tubitak.gov.tr/sites/default/files/303/4006_bilim_fuarlari_k ilavuzu. pdf

TÜBİTAK (2019b), 8. Bilim Fuarları Destekleme Programı, Erişim adresi: https://www.tubitak.gov.tr/sites/default/files/303/4006_bilgilendirme_s unumu 2019.pdf

Türk Dil Kurumu (2011), Türkçe Sözlük, Türk Dil Kurumu Yayınları, 
Ankara.

Türkmen, Hakan (2019), “The Impact of Science Fairs on Adults' Scientific Perceptions \& Scientific Epistemological Beliefs”, Malaysian Online Journal of Educational Sciences, 7(3), ss. 22-32.

Yıldırım, Halil İbrahim (2018), "Bilim Şenliklerinin Ortaokul 6. Sınıf Öğrencilerinin Problem Çözme Becerilerine Etkisi”, Trakya Üniversitesi Eğitim Fakültesi Dergisi, 8(2), ss. 390-409.

Yıldırım, Halil İbrahim (2020), "Bilim Fuarında Projeyle Yer Alan Öğrencilerin ve Danışman Öğretmenlerin Bilim Fuarına İlişkin Görüşleri”, e- Kafkas Eğitim Araştırmaları Dergisi, 7, ss. 28-51. 
G. Selcuk-E.H. Atalmıs-A. Atac Öğgretmen ve Öğgrencilere Göre 4006...

EK:

\begin{tabular}{|c|c|c|c|c|c|c|}
\hline & Öğrencilere Göre 4006 TÜBITAK Bilim Fuarları E & & & & & \\
\hline & $\begin{array}{l}\text { 1= Hiç Katılmıyorum; 2= Çok Az Düzeyde Kat } \\
\text { 3=Orta Düzeyde Katılıyorum; }\end{array}$ & Illy & ory & & & \\
\hline & İFADELER & 1 & 2 & 3 & 4 & 5 \\
\hline 1 & Öğrencinin kendine olan özgüvenini artırır. & & & & & \\
\hline 2 & Öğrenciye bilimsel düşünme becerisi kazandırır. & & & & & \\
\hline 3 & Öğrencinin araştırma becerisini artırır. & & & & & \\
\hline 4 & Öğrencinin yaratıcılık becerisini artırır. & & & & & \\
\hline 5 & Öğrencinin işbirliği içinde çalışmasını sağlar. & & & & & \\
\hline 6 & $\begin{array}{l}\text { Öğrenciye yeni bir ürün ortaya çıkarmanın hazzını } \\
\text { yaşatır. }\end{array}$ & & & & & \\
\hline 7 & Öğrencinin bilime karşı ilgi ve isteğini artırır. & & & & & \\
\hline 8 & Öğrencinin sorumluluk alma bilincini geliştirir. & & & & & \\
\hline 9 & $\begin{array}{l}\text { Öğrenciye öğrendiklerini günlük yaşamda kullanma } \\
\text { fırsatı sağlar. }\end{array}$ & & & & & \\
\hline 10 & Öğrenciye kendini değerli hissettirir. & & & & & \\
\hline 11 & Öğrencinin sosyalleşmesini sağlar. & & & & & \\
\hline 12 & Öğrencinin aktif bir şekilde öğrenmesini sağlar. & & & & & \\
\hline$\overline{13}$ & Öğrenciyi yeni bir şey keşfetmesi heyecanını yaşatır. & & & & & \\
\hline
\end{tabular}




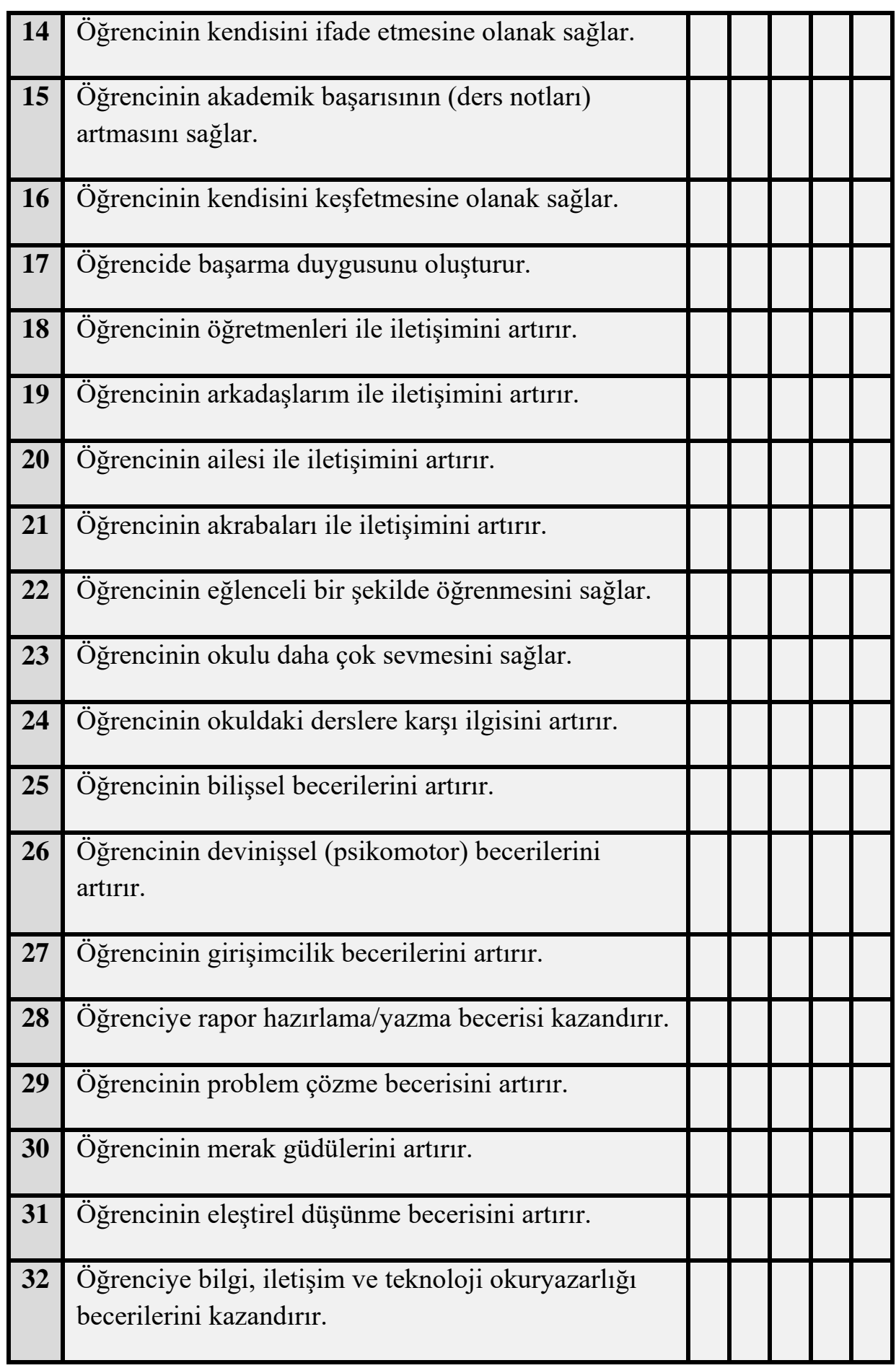


G. Selcuk-E.H. Atalmıs-A. Atac Öğretmen ve Öğrencilere Göre 4006...

\begin{tabular}{|c|c|}
\hline 33 & Öğrenciye kendine yön verme becerisi kazandırır. \\
\hline 34 & $\begin{array}{l}\text { Öğrenciye sosyal ve kültürler arası beceriler } \\
\text { kazandırır. }\end{array}$ \\
\hline 35 & Öğrenciye liderlik bakış açısı kazandırır. \\
\hline
\end{tabular}

Öğretmenlere Göre 4006 TÜBITAK Bilim Fuarları Etkililik Ölçeği

1= Hiç Katılmıyorum; 2= Çok Az Düzeyde Katılıyorum;

3=Orta Düzeyde Katılıyorum;

4= Büyük Ölçüde Katılıyorum; 5= Tamamen Katılıyorum

İFADELER

\begin{tabular}{|l|l|l|l|l|l|l|}
\hline \multicolumn{2}{|l|}{ TÜBİTAK 4006 Projelerinin Öğrenciye Katkısı } & 1 & 2 & 3 & 4 & 5 \\
\hline $\mathbf{1}$ & $\begin{array}{l}\text { Öğrencinin bilimsel olarak düşünme becerisini } \\
\text { geliştirir. }\end{array}$ & & & & & \\
\hline 2 & Öğrencinin araştırma becerisini geliştirir. & & & & & \\
\hline 3 & Öğrencinin keşfetme becerisini geliştirir. & & & & & \\
\hline 4 & Öğrencinin özgüvenini artırır. & & & & \\
\hline 5 & Öğrencilerin yaratıcılık becerisini artırır. & & & & & \\
\hline 6 & Öğrencinin öğrenmeye karşı motivasyonunu artırır. & & & & \\
\hline 7 & Öğrencilerin öz yeterlilik algısını geliştirir. & & & & \\
\hline
\end{tabular}




\begin{tabular}{|c|c|c|c|c|c|c|}
\hline 8 & Öğrencinin yaparak yaşayarak öğrenmesini sağlar. & & & & & \\
\hline 9 & Öğrencinin eğlenceli bir şekilde öğrenmesini sağlar. & & & & & \\
\hline 10 & Öğrencilerin paylaşma duygusunu geliştirir. & & & & & \\
\hline 11 & Öğrencilerin issbirliği becerilerini geliștirir. & & & & & \\
\hline 12 & $\begin{array}{l}\text { Öğrencilerin bilimsel farkındalık duygularını } \\
\text { geliştirir. }\end{array}$ & & & & & \\
\hline 13 & $\begin{array}{l}\text { Öğrencilerin bilgiyi günlük hayatta kullanmalarına } \\
\text { olanak sağlar. }\end{array}$ & & & & & \\
\hline 14 & Öğrencilerin sosyalleşmelerine katkı sağlar. & & & & & \\
\hline 15 & Öğrencilerin başarı güdülerini artırır. & & & & & \\
\hline 16 & Öğrencilerin mutluluklarını artırır. & & & & & \\
\hline 17 & Öğrencilerin düzenli çalıșma becerilerini artırır. & & & & & \\
\hline 18 & Öğrencilerin sorumluluk duygularını gelistirir. & & & & & \\
\hline 19 & Öğrencilerin problem çözme becerilerini geliștirir. & & & & & \\
\hline 20 & Öğrencilerin akademik başarılarını artırır. & & & & & \\
\hline 21 & Öğrencilerin girişimcilik becerilerinin artırır. & & & & & \\
\hline 22 & Öğrencilerin derslere karşı ilgisini artırır. & & & & & \\
\hline \multicolumn{2}{|r|}{ TÜBİTAK 4006 Projelerinin Öğretmene Katkısı } & 1 & 2 & 3 & 4 & $\overline{5}$ \\
\hline 1 & Öğretmen - yönetim arasındaki iletișimi artırır. & & & & & \\
\hline 2 & $\begin{array}{l}\text { Öğretmenlerin mesleki anlamda monotonluktan } \\
\text { uzaklaşmalarına olanak sağlar. }\end{array}$ & & & & & \\
\hline 3 & Öğretmenleri mesleki anlamda geliştirir. & & & & & \\
\hline
\end{tabular}


G. Selcuk-E.H. Atalmıs-A. Atac Öğretmen ve Öğrencilere Göre 4006...

\begin{tabular}{|c|c|c|c|c|c|c|}
\hline 4 & Öğretmenleri mesleki anlamda heyecanlarını artırır. & & & & & \\
\hline 5 & Öğretmenlerin merak duygularını geliştirir. & & & & & \\
\hline 6 & Öğretmenlerin bilimsel kazanımlarını artırır. & & & & & \\
\hline 7 & Öğretmenlerin düșünme becerilerini geliștirir. & & & & & \\
\hline 8 & $\begin{array}{l}\text { Öğretmenlerin proje kavramına olumlu bakış açısı ile } \\
\text { yaklaşmasına olanak sağlar. }\end{array}$ & & & & & \\
\hline 9 & $\begin{array}{l}\text { Öğretmenlerin proje hazırlama sürecini öğrenmesini } \\
\text { sağlar. }\end{array}$ & & & & & \\
\hline 10 & $\begin{array}{l}\text { Öğretmenlerin dersleri daha etkili bir şekilde } \\
\text { anlatmasına olanak sağlar. }\end{array}$ & & & & & \\
\hline 11 & Öğretmenlerde başarma duygusunu geliştirir. & & & & & \\
\hline 12 & $\begin{array}{l}\text { Öğretmenlerin organizasyon yapma becerilerini } \\
\text { geliştirir. }\end{array}$ & & & & & \\
\hline 13 & Öğretmenlerin sorumluluk alma becerilerini artırır. & & & & & \\
\hline 14 & Öğretmenlerin özgüvenlerini artırır. & & & & & \\
\hline 15 & $\begin{array}{l}\text { Öğretmenlerin öğrettiklerinin uygulamada var olduğu } \\
\text { duygusunu kazandırır. }\end{array}$ & & & & & \\
\hline \multicolumn{2}{|r|}{ TÜBİTAK 4006 Projelerinin Veliye Katkısı } & 1 & 2 & 3 & 4 & 5 \\
\hline 1 & Velilerin okula bakış açılarını olumlu yönde değiştir. & & & & & \\
\hline 2 & Veli-okul arasındaki iletişimi artırır. & & & & & \\
\hline 3 & Veli-öğretmen arasındaki iletişimi artırır. & & & & & \\
\hline 4 & Veli-öğrenci arasındaki iletişimi artırır. & & & & & \\
\hline
\end{tabular}




\begin{tabular}{|l|l|l|l|l|l|}
\hline $\mathbf{5}$ & $\begin{array}{l}\text { Velinin eğitim-öğretim sürecine katılmasında olumlu } \\
\text { bir katkı sağlar. }\end{array}$ & & & & \\
\hline $\mathbf{6}$ & Veli-okul arasındaki işbirliğini geliştirir. & & & & \\
\hline $\mathbf{7}$ & Veli-öğrenci arasındaki işbirliği geliştirir. & & & & \\
\hline $\mathbf{8}$ & Veli-öğretmen arasındaki işbirliğini geliştirir. & & & & \\
\hline $\mathbf{9}$ & $\begin{array}{l}\text { Velilerin TÜBİTAK'ın varlığını öğrenmesinde etkili } \\
\text { olur. }\end{array}$ & & & & \\
\hline
\end{tabular}

